\title{
Letter to the editor re: ICP monitoring guidelines for TBI
}

\author{
Paul Steinbok $^{1}$
}

Received: 30 November 2015 / Accepted: 18 December 2015 /Published online: 8 January 2016

(C) Springer-Verlag Berlin Heidelberg 2016

Dear Editor:

Child's Nervous System:

I read with interest the paper by Roumeliotis et al. "ICP monitoring in children: why are we not adhering to guidelines?" [1]. The authors state as the premise for their study: "Current adult and pediatric guidelines for the management of severe TBI suggest that patients should undergo invasive intracranial pressure (ICP) monitoring, despite a lack of grade 1 evidence." In the abstract, they state further that "despite pediatric guidelines, variability exists in the management of severe traumatic brain injury (TBI), as somewhere between 7 and $60 \%$ of children undergo intracranial pressure (ICP) monitoring. Reasons for this low adherence to TBI management guidelines remain unclear." Hence, the reason for their study to identify how often these guidelines were being adhered to and if not, what were the reasons.

Clearly, the authors have decided that according to the published guidelines, surgeons should be monitoring ICP in children with severe TBI. In my opinion, this is a misrepresentation of what is stated in the guidelines. As stated in the pediatric head injury guidelines [2], "Use of intracranial pressure (ICP) monitoring may be considered in infants and children with severe traumatic brain injury (TBI)," and this is based on

Paul Steinbok

psteinbok@cw.bc.ca

1 BC Children's Hospital, Vancouver, BC, Canada
Level 3 evidence. There was no Level 1 or even Level 2 evidence to support ICP monitoring. The use of ICP monitoring was, as Kochanek et al. indicated, a "weak" recommendation [2]. Roumeliotis et al. are incorrect in stating that the guidelines "suggest that patients should undergo ICP monitoring."

ICP monitoring in pediatric TBI is just is an option to consider, and as such, it would be expected that neurosurgeons will have different thresholds for ICP monitoring. I suspect that if high-quality studies indicated a patient population where ICP monitoring is recommended with even Level 2 evidence, neurosurgeons would adhere to that type of recommendation almost universally. That is not the current situation.

I have no issue with those who routinely place ICP monitors in children with severe TBI, but I think we should all continue to recognize that this is just an option and definitely not a standard of care. We should not be critical of those who choose not to place ICP monitors routinely in children with severe TBI.

\section{References}

1 Roumeliotis N, Pettersen G, Crevier L, Emeriaud G (2015) ICP monitoring in children: why are we not adhering to guidelines? Childs Nerv Syst 31:2011-2014

2 Kochanek PM, Carney N, Adelson PD, Ashwal S, Bell MJ, Bratton S, Carson S, Chesnut RM, Ghajar J, Goldstein B, Grant GA, Kissoon N, Peterson K, Selden NR, Tasker RC, Tong KA, Vavilala MS, Wainwright MS, Warden CR (2012) Guidelines for the acute medical management of severe traumatic brain injury in infants, children, and adolescents-second edition. Pediatr Crit Care Med 13(Suppl 1):S1-82 